\title{
Systemic Reduction in Glutathione Levels Occurs in Patients with Primary Open-Angle Glaucoma
}

\author{
Doina Gherghel, ${ }^{1,2}$ Helen Rosemary Griffitbs, ${ }^{1}$ Emma Jane Hilton, ${ }^{1,2}$ Ian Andrew Cunliffe, ${ }^{2}$ \\ and Sarab Louise Hosking ${ }^{1,2}$
}

Purpose. To assess the level of plasma glutathione in patients with untreated primary open-angle glaucoma.

Methods. Twenty-one patients with newly diagnosed primary open-angle glaucoma and 34 age- and gender-matched control subjects were subjected to a blood analysis to detect the level of circulating glutathione in its reduced and oxidized forms The effect of age, gender, and systemic blood pressure on circulating glutathione levels was also analyzed.

RESULTS. Age had a negative effect on the level of both reduced and total glutathione $(P=0.002, r=-0.52$ and $P=0.002, r=$ -0.52 , respectively) in control subjects but not in patients with glaucoma $(P>0.05, r=0.27$, and $P>0.05, r=0.22$, respectively). In the control group, men demonstrated higher levels of both reduced and total glutathione than did women ( $P=0.024$ and $P=0.032$, respectively). After correction for age and gender influences on blood glutathione levels, patients with glaucoma exhibited significantly lower levels of reduced and total glutathione than did control subjects $(P=0.010, \mathrm{~F}=$ 7.24 and $P=0.006, \mathrm{~F}=8.38$, respectively). No differences between study groups were observed in either oxidized glutathione levels or redox index $(P>0.05, \mathrm{~F}=0.50$; and $P>0.05$, $\mathrm{F}=0.30$, respectively)

Concuusions. Patients with glaucoma exhibit low levels of circulating glutathione, suggesting a general compromise of the antioxidative defense. (Invest Ophthalmol Vis Sci. 2005;46: 877-883) DOI:10.1167/iovs.04-0777

$\mathrm{P}$ rimary open-angle glaucoma (POAG) is a chronic, slowly progressive optic neuropathy, characterized by excavation of the optic nerve head $(\mathrm{ONH})$ and a distinctive pattern of visual field (VF) defects. ${ }^{1}$ The disease is multifactorial in origin and is associated more closely with elevated intraocular pressure (IOP) resulting in the main from reduced drainage of aqueous humor. Nevertheless, approximately one third of patients with glaucoma exhibit apparently normal IOP. Moreover, a substantial number of POAG cases continue to progress despite therapeutically lowered IOP. All these observations have spurred further research to determine the existence of other possible risk factors for glaucoma. ${ }^{2}$

Besides more extensively investigated factors, such as increased IOP, ${ }^{3,4}$ reduced ocular blood flow (OBF), ${ }^{5-9}$ ocular

From the ${ }^{1}$ School of Life and Health Sciences, Aston University, Birmingham, United Kingdom; and the ${ }^{2}$ Department of Ophthalmology, Heartlands and Solihull NHS Trust, Birmingham, United Kingdom.

Submitted for publication July 1, 2004; revised October 7, 2004; accepted November 10, 2004.

Disclosure: D. Gherghel, None; H.R. Griffiths, None; E.J. Hilton, None; I.A. Cunliffe, None; S.L. Hosking, None

The publication costs of this article were defrayed in part by page charge payment. This article must therefore be marked "advertise ment" in accordance with 18 U.S.C. $\$ 1734$ solely to indicate this fact.

Corresponding author: Helen Griffiths, School of Life and Health Sciences, Aston University, Aston Triangle, Birmingham B4 7ET, UK; h.r.griffiths@aston.ac.uk. vascular dysregulation, ${ }^{10-16}$ and systemic blood pressure (BP) alterations, ${ }^{17-21}$ oxidative stress has also been proposed as a contributing factor in the etiology of glaucomatous optic neuropathy. ${ }^{22-26}$ Oxidative stress represents a harmful state defined by the presence of pathologic levels of reactive oxygen species (ROS) relative to antioxidant defense. ROS are molecules that oxidize more strongly than oxygen $\left(\mathrm{O}_{2}\right)$ itself, or molecules containing oxygen that generate free radicals. ROS include superoxide $\left(\mathrm{O}_{2}{ }^{-}\right)$, hydrogen peroxide $\left(\mathrm{H}_{2} \mathrm{O}_{2}\right)$ and hydroxyl radical $(\mathrm{OH} \cdot)$, which is the strongest oxidant produced in biological systems. Other reactive species, reactive nitrogen species (RNS), include nitric oxide and peroxynitrite $\left(\mathrm{ONOO}^{-}\right)$, a product resulting from the reaction between ROS and nitric oxide $(\mathrm{NO})$.

In certain situations, free radicals can be generated in an exaggerated manner and can injure tissues and organs by interacting with lipids, proteins, or DNA. ${ }^{27}$ Oxidative stress has been implicated in a large number of human diseases, including different autoimmune diseases, ${ }^{28}$ alcoholic liver disease, ${ }^{29}$ cancer, ${ }^{30}$ and infection with human immunodeficiency virus $(\mathrm{HIV})^{31}$ and in ischemia-reperfusion injury. ${ }^{32}$

To survive, the human body has developed a complex, efficient, and highly adaptive antioxidant defense system that includes two categories of antioxidants: (1) enzymatic, such as glutathione peroxidase (GPx), glutathione reductase (GSSGR), superoxide dismutase (SOD), catalase (CAT), and peroxiredoxin, ${ }^{33}$ and (2) nonenzymatic, such as reduced glutathione (GSH), antioxidant vitamins, and low-molecular-weight compounds such as urate. ${ }^{34}$

The eye is also protected against oxidative stress by several mechanisms involving antioxidant enzymes such as CAT and SOD, as well as by low-molecular-weight antioxidants such as GSH and ascorbate. ${ }^{35}$ Glutathione (GSH, L- $\gamma$-glutamyl-t-cysteinylglycine), a tripeptide consisting of glycine, cysteine, and glutamic acid, prevents the effects of ROS either directly as an antioxidant or indirectly, by maintaining other cellular antioxidants in a functional state. ${ }^{36,37} \mathrm{GSH}$ conjugates with a large variety of products of oxidative stress and carcinogens via reactions facilitated by the enzyme glutathione S-transferase (GST). In living organisms, glutathione exists in two forms: reduced (GSH) and oxidized (GSSG). An optimal GSH: GSSG ratio is critical for survival of the cells and tight regulation of the system is therefore very important. ${ }^{38}$

Abnormal levels of GSH have already been reported in the lens $^{39-41}$ and whole blood ${ }^{42}$ of patients with age-related cataract, in the vitreous humor, in the blood of patients with proliferative diabetic retinopathy (PDR) or proliferative vitreoretinopathy (PVR), ${ }^{43}$ and in the blood of patients with agerelated macular degeneration (ARMD). ${ }^{44,45}$ Altered GSH and GSH activity has also been reported in the trabecular meshwork and aqueous humor of patients with glaucoma. ${ }^{23-26}$ In a recent study, Yang et al. ${ }^{46}$ demonstrated the presence of serum antibodies against GST in patients with glaucoma. The results of these studies are of extreme importance. A deficit in the scavenging capacity of GSH could reduce the bioavailability of NO for vasodilation, with consequent disruption of vascular 
TABLE 1. Reagents and Equipment Used for the GSH Assay

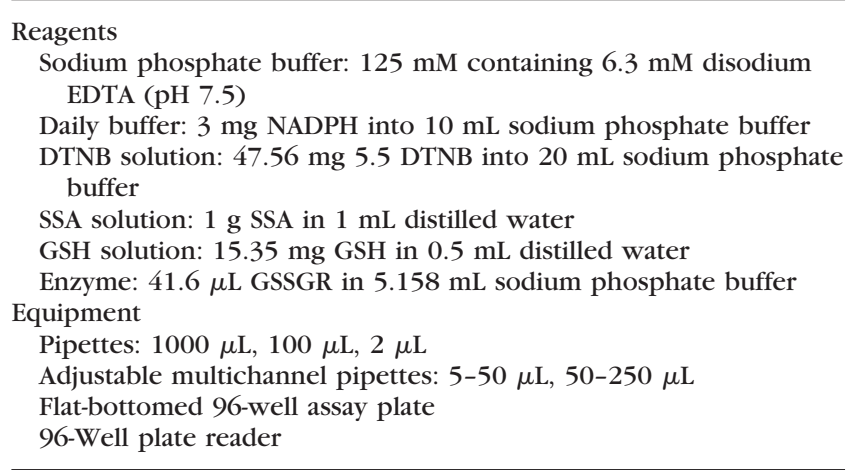

tone. Although a deficit in NO could result in altered ocular perfusion pressure (OPP) in glaucoma, ${ }^{47}$ to date no study has been undertaken to investigate whether altered systemic GSH levels occur in patients who have this disease. Consequently, it is important to determine whether there is a relationship between circulating levels of GSH and the occurrence of POAG. The purpose of the present study was to establish circulating GSH and GSSG levels in patients with newly diagnosed and previously untreated POAG.

\section{Subjects ANd Methods}

\section{Study Sample}

Consecutive patients with newly diagnosed and previously untreated POAG attending the Fast Track Glaucoma Clinic at the Heartlands and Solihull NHS Trust (Birmingham, UK) between February 2002 and December 2003, were considered for inclusion in this prospective study. Ethical approval was obtained from the local medical ethics committee, and written informed consent was received from all subjects before entry into the study. The study was designed and conducted in accordance with the tenets of Declaration of Helsinki.

Patients underwent diurnal IOP phasing and were diagnosed as having POAG if IOP measurements were greater than $21 \mathrm{~mm} \mathrm{Hg}$ by applanation tonometry (with at least two of the measurements being higher than $24 \mathrm{~mm} \mathrm{Hg}$ ), glaucomatous cupping of the optic disc on fundoscopic examination, normal open anterior chamber angles by gonioscopy, and repeatable VF defects consistent with the diagnosis of glaucoma, according to results obtained with program 24-2 of the Humphrey Field Analyzer (HFA: Carl Zeiss Meditec, Dublin, CA). The study's ocular exclusion criteria included narrow iridocorneal angles, evidence of secondary open-angle glaucoma, history of previous intraocular surgery, and other nonglaucomatous ocular diseases including cataract, diabetic retinopathy (DR) and ARMD. Forty-six patients with previously untreated glaucoma were screened during the study period. However, only 33 patients met these first criteria.

The control group was recruited from patients' spouses and from other volunteers, and it was composed of subjects who had never neither glaucoma nor other ocular diseases such as cataract, DR, or ARMD.

Other exclusion criteria for both groups were smoking and a history of any chronic systemic disease with presumed low GSH levels, including autoimmune diseases ${ }^{28}$ alcoholic liver disease,${ }^{29}$ cancer, ${ }^{30}$ and diabetes mellitus. ${ }^{48}$ After this selection, the experimental group was narrowed to 21 patients with glaucoma and 34 control subjects.

\section{BP Measurement}

$\mathrm{BP}$ was measured in each patient and control subject in the morning between 8 and 9 AM, with a BP monitor (UA-779; A\&D Instruments, Ltd., Oxford, UK). In preparation for this measurement, each subject rested in a sitting position for approximately 10 minutes in a quiet

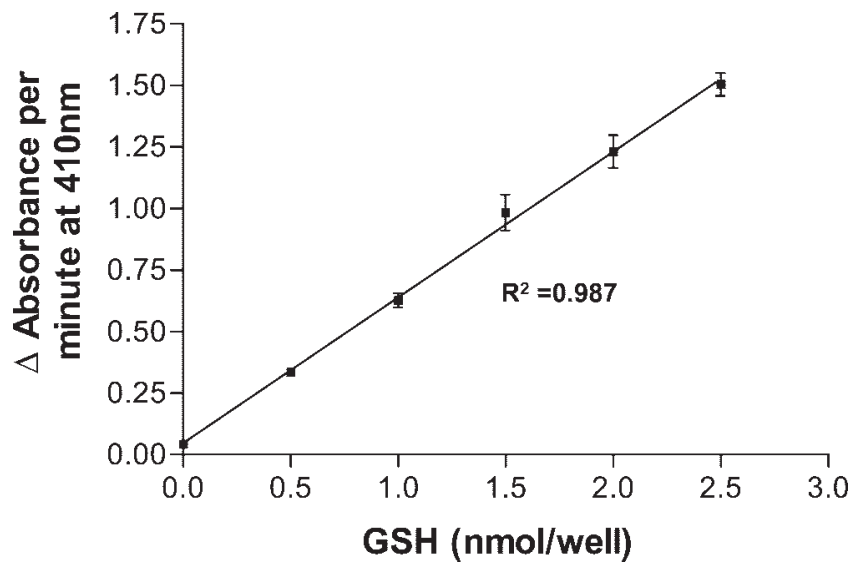

FIGURE 1. The standard curve for the GSH assay.

room to achieve sufficient mental and physical calm. The systolic BP (SBP) and diastolic BP (DBP) were measured three times (1 minute apart). The average readings for SBP and DBP were then used to calculate the mean $\mathrm{BP}(\mathrm{MBP})$ using the formula: $\mathrm{MBP}=2 / 3 \mathrm{DBP}+1 / 3 \mathrm{SBP}$.

\section{Blood Sampling}

Subjects were instructed to fast between 9 PM and retiring on the evenings before the blood drawing. On the morning of the test, subjects were requested to have only a light breakfast, such as simple toast. They were asked to avoid any cooked breakfast, meat, cereal, fresh fruits, fruit juice, and any nutritional supplements. ${ }^{49}$ Subjects were also asked to abstain from caffeinated beverages and chocolate and from alcohol for at least 2 hours before the visit.

All blood samples were obtained by a qualified phlebotomist in the morning, between 9 and $10 \mathrm{AM}$. Seven milliliters of blood was collected in EDTA-treated tubes (to prevent oxidation ${ }^{50}$ ) by venipuncture to the antecubital vein. Thirty microliters of blood was then transferred into centrifuge tubes for initial processing. The GSH was released from the blood cells by protein precipitation and cellular disruption achieved by addition of $33.3 \mu \mathrm{L}$ of 5-sulfosalicylic acid (SSA), 100 $\mathrm{mg} / \mathrm{mL}$ within 10 minutes from the blood collection. ${ }^{51}$ Each sample was then diluted with $936.7 \mu \mathrm{L}$ sodium phosphate buffer ( $\mathrm{pH} 7.5$ ), and the content of each tube was mixed rapidly in a centrifuge at 13,000 rpm for 5 minutes. A portion of supernatant $(150 \mu \mathrm{L})$ was then collected into clean centrifuge tubes and immediately cooled at $-70^{\circ} \mathrm{C}$. Samples stored at this temperature are stable for at least 2 months and can be transported on dry ice without deterioration. ${ }^{52}$

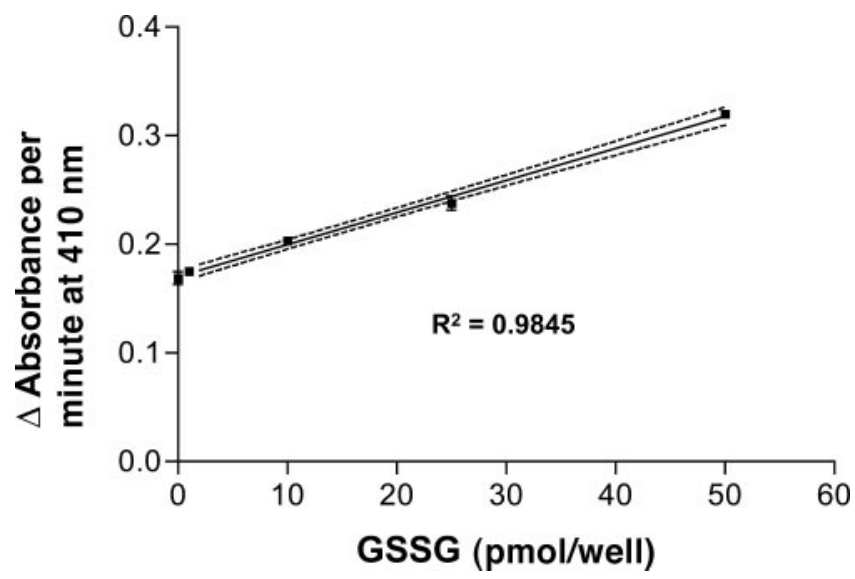

FIGURE 2. The standard curve for the GSSG assay. 
Table 2. Characteristics of the Study Groups

\begin{tabular}{lccc}
\hline Parameter & $\begin{array}{c}\text { Glaucoma Patients } \\
(\boldsymbol{n}=\mathbf{2 1})\end{array}$ & $\begin{array}{c}\text { Control Subjects } \\
(\boldsymbol{n}=\mathbf{3 4})\end{array}$ & $\boldsymbol{P}$ \\
\hline Age (y) & $72.40 \pm 11.00$ & $68.45 \pm 10.11$ & $>0.05$ \\
IOP (mm Hg) & $24.04 \pm 5.47$ & $18.68 \pm 3.59$ & $<0.001$ \\
MD (dB) & $-5.03 \pm 7.47$ & $-1.05 \pm 2.00$ & $=0.020$ \\
PSD (dB) & $5.74 \pm 3.62$ & $1.70 \pm 0.42$ & $<0.001$ \\
SBP (mm Hg) & $142.72 \pm 20.95$ & $142.24 \pm 23.66$ & $>0.05$ \\
DBP (mm Hg) & $79.99 \pm 12.34$ & $82.76 \pm 12.36$ & $>0.05$ \\
MBP (mm Hg) & $100.90 \pm 13.58$ & $102.58 \pm 15.24$ & $>0.05$ \\
\hline
\end{tabular}

\section{Blood Analysis}

GSH Assay. The total GSH levels (t-GSH) were assessed by the GSSGR-DTNB (5.5 dithiobis-2-nitrobenzoic acid) recycling procedure, as described in previous studies. ${ }^{50,53}$ The reagents and equipment used for this assay are listed in Table 1 .

A standard curve from 0 to 2 nanomoles in 0.5 -nanomole increments using GSH solution $(0.2-0.8 \mu \mathrm{L})$ was prepared. The standards contained the same final concentrations of SSA as for the samples (1\%). To each well of a 96-well plate, $150 \mu \mathrm{L}$ of daily buffer (see Table 1), 50 $\mu \mathrm{L}$ of DTNB solution, and $25 \mu \mathrm{L}$ of standards or samples were added in quadruplicate, and the plate was incubated at $37^{\circ} \mathrm{C}$ for 3 minutes. Finally, $25 \mu \mathrm{L}$ GSSGR was added to the previous mixture, and the plate was read at $410 \mathrm{~nm}$ using a 96-well plate reader. ${ }^{54} \mathrm{~A}$ standard curve was then generated by linear regression (Excel; Microsoft, Redmond, WA; Fig. 1).

GSSG Assay. The GSSG levels were assessed with a DTNB-GSSGR recycling assay. ${ }^{50}$ The reagents used in this assay were those described in Table 1 and, in addition, triethanolamine (TEA) and 2-vinyl pyridine (2-VP). TEA prevents a high local $\mathrm{pH}$ and oxidation, whereas 2-VP is used to stabilize GSH.

A GSSG standard curve from 0 to 0.25 nanomole, in 0.025 -nanomole increments was prepared. Standards and samples $(100 \mu \mathrm{L})$ were transferred into separate centrifuge tubes and $2 \mu \mathrm{L} 2-\mathrm{VP}$ was added to each tube. TEA was then used to adjust the $\mathrm{pH}$ of the standards/ samples to 7.5 .

To each well of the 96-well plate, $150 \mu \mathrm{L}$ of daily buffer, $50 \mu \mathrm{L}$ of DTNB solution, and $25 \mu \mathrm{L}$ of standards or samples were added in quadruplicate, and the plate was incubated at $37^{\circ} \mathrm{C}$ for 3 minutes. Finally, $25 \mu \mathrm{L}$ of GSSGR was added to the previous mixture, and the plate was read at $410 \mathrm{~nm}$ with a $96-$-well plate reader. A standard curve was then generated by linear regression (Excel Microsoft; Fig. 2).

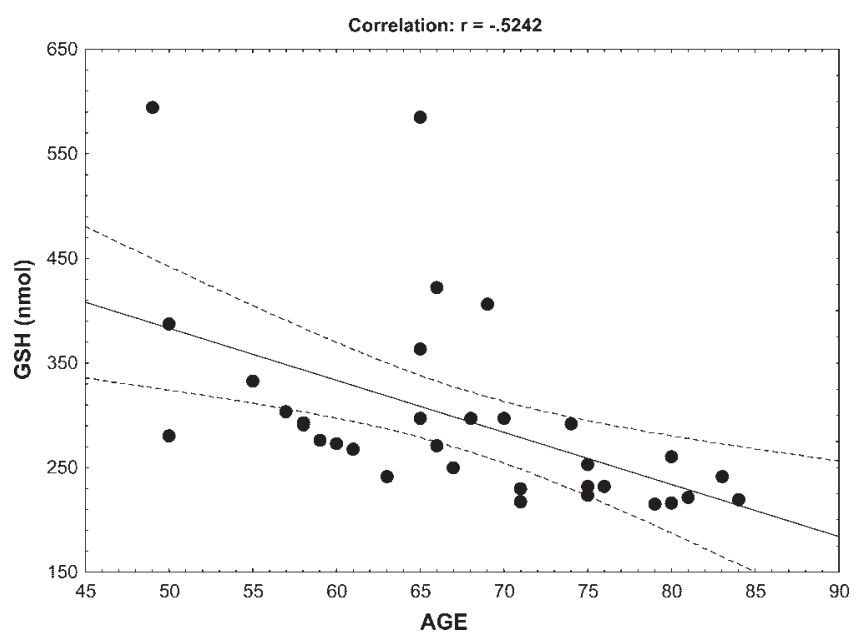

FIGURE 3. The influence of age on plasma GSH levels.
Finally, the GSH levels (GSH = t-GSH - GSSG) and the redox index (defined as the GSH to GSSG ratio) were calculated.

\section{Statistical Analysis}

The statistical analysis was performed on computer (Statistica for Windows; StatSoft, Tulsa, OK). Data are expressed as the mean \pm SD. Differences between groups at baseline for age, gender, and systemic BP parameters were calculated using Student's $t$-test for unpaired variables. A multivariate analysis was performed to test the influence of age, gender, and systemic BP on blood GSH levels. Differences between the two study groups in blood GSH levels were computed by analysis of covariance (ANCOVA). $P<0.05$ was considered statistically significant.

\section{RESUlts}

Twenty-one patients with POAG ( 7 men and 14 women) and 34 control subjects (15 men and 19 women) years were included in the study. The characteristics of the study groups are given in Table 2. There was no significant difference in age and systemic BP between patients with glaucoma and control subjects $(P>0.05)$; however, there were significant differences in IOP $(P<0.001)$, and the measured VF parameters (mean deviation $[\mathrm{MD}] P=0.020$ and pattern standard deviation $[\mathrm{PSD}] P<0.001$, respectively).

\section{The Effect of Age and SBP}

In the control group, age had a negative effect on the level of both GSH $(P=0.002, r=-0.52$; Fig. 3$)$ and t-GSH $(P=0.002$, $r=-0.52$; Fig. 4) but not on the level of GSSG and redox index $(P>0.05, r=-0.17$; and $P>0.05, r=-0.25$, respectively). In patients with glaucoma, however, blood GSH

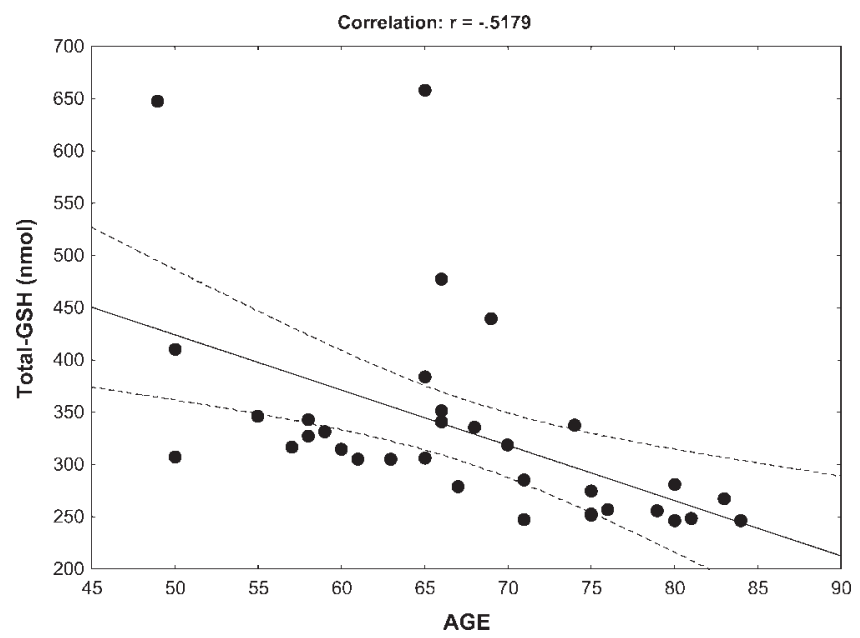

Figure 4. The influence of age on t-GSH levels. 
TABLE 3. Gender Influence on Blood GSH Levels

\begin{tabular}{|c|c|c|c|c|c|c|}
\hline \multirow[b]{2}{*}{ Parameter } & \multicolumn{3}{|c|}{ Glaucoma Patients $(n=21)$} & \multicolumn{3}{|c|}{ Control Subjects $(n=34)$} \\
\hline & $\begin{array}{c}\text { Men } \\
(n=7)\end{array}$ & $\begin{array}{c}\text { Women } \\
(n=14)\end{array}$ & $\boldsymbol{P}$ & $\begin{array}{c}\text { Men } \\
(n=15)\end{array}$ & $\begin{array}{c}\text { Women } \\
(n=19)\end{array}$ & $\boldsymbol{P}$ \\
\hline GSH (nmol) & $225.42 \pm 111.50$ & $224.85 \pm 87.36$ & $>0.05$ & $338.47 \pm 120.32$ & $265.62 \pm 50.68$ & $=0.024$ \\
\hline GSSG (nmol) & $34.13 \pm 8.94$ & $25.22 \pm 20.80$ & $>0.05$ & $36.10 \pm 16.98$ & $34.94 \pm 18.09$ & $>0.05$ \\
\hline Redox index (GSH/GSSG) & $10.29 \pm 7.13$ & $9.13 \pm 6.27$ & $>0.05$ & $10.90 \pm 5.24$ & $10.24 \pm 7.72$ & $>0.05$ \\
\hline $\mathrm{t}-\mathrm{GSH}(\mathrm{nmol})$ & $249.93 \pm 96.45$ & $258.98 \pm 80.44$ & $>0.05$ & $372.35 \pm 126.16$ & $300.55 \pm 54.85$ & $=0.032$ \\
\hline
\end{tabular}

levels were not significantly influenced by age (GSH: $P>0.05$, $r=0.27$; t-GSH: $P>0.05, r=0.22$; GSSG: $P>0.05, r=$ -0.27 ; and redox index: $P>0.05, r=0.25)$. There was no significant association between blood GSH levels and systemic $\mathrm{BP}$ in either of the study groups $(P>0.05)$.

\section{Gender Effect}

There were no differences in the proportion of men and women included in the study groups $\left(P>0.05, \chi^{2}\right.$ test). The relationship between gender and blood GSH levels is illustrated in Table 3. In the control group, men demonstrated higher levels of both GSH ( $P=0.024$; Fig. 5$)$ and t-GSH $(P=0.032$; Fig. 6). GSSG and redox index levels were similar in both men and women $(P>0.05)$. In the glaucoma group, men and women had similar levels of blood GSH $(P>0.05)$.

\section{Intergroup Differences in Blood GSH}

Table 4 shows blood GSH and GSSG levels in both study groups. After correcting for age and gender influence on blood GSH levels, patients with glaucoma exhibited significantly lower levels of GSH and t-GSH than control subjects $(P=$ $0.010, \mathrm{~F}=7.24$; and $P=0.006, \mathrm{~F}=8.38$, respectively; Figs. 7 8). There were no significant differences between study groups in GSSG levels and redox index $(P>0.05, \mathrm{~F}=0.50$; and $P>0.05, \mathrm{~F}=0.33$, respectively).

\section{Discussion}

The present study assessed the circulating GSH and GSSG levels in patients with newly diagnosed and previously untreated POAG. Our results disclosed that, independent of age and gender, patients with glaucoma demonstrated lower GSH

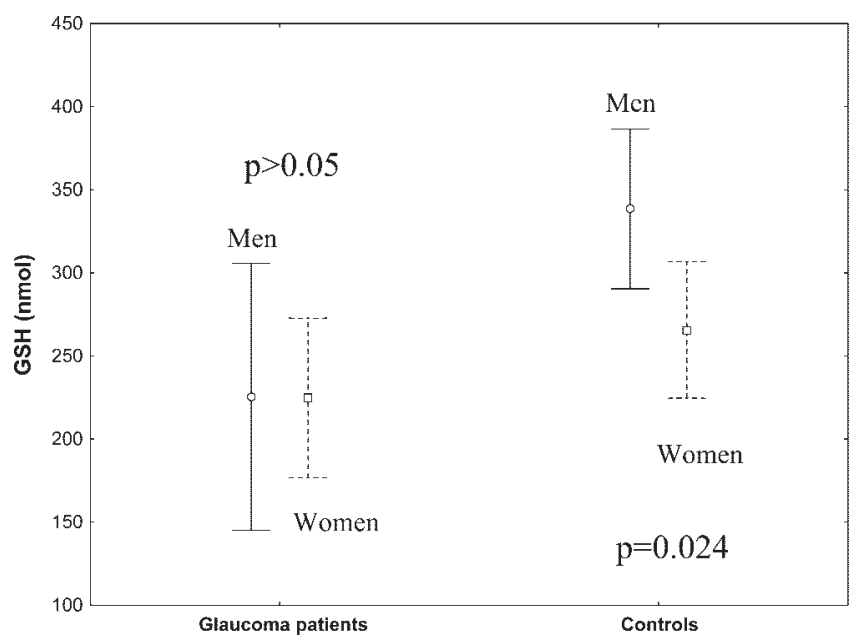

Figure 5. Men demonstrated higher levels of GSH than did women in the control group, but not the POAG group. and t-GSH levels than age-matched control subjects. GSSG levels and redox index, however, were similar in both study groups.

GSH is among the most efficient substances that cells and tissues use in their defense against oxidative stress. ${ }^{37}$ Age and disease, however, act to decrease the amount of GSH available in the organism. It has been demonstrated that at least half of apparently healthy elderly individuals show low blood GSH levels. ${ }^{55-57}$ Indeed, our results show a negative correlation between age and both GSH and t-GSH levels in control subjects. This effect was lost in the glaucoma group. In the general population, age is strongly associated with increased oxidative stress and reduced antioxidant status. ${ }^{58}$ The loss of this correlation between age and GSH loss in patients with POAG demonstrated in the present study could indicate that a more important, independent factor than age influences GSH levels in this cohort.

It has been shown that blood GSH levels are influenced by gender, with men demonstrating higher levels than women. ${ }^{59}$ Our results also show that in control subjects, men had higher levels of GSH and t-GSH than did women. Nevertheless, in patients in the glaucoma group both genders demonstrated similar blood GSH levels, which again suggests an overriding modulation of GSH in POAG that exceeds that afforded by either gender or age.

Clinical and laboratory studies performed so far have demonstrated a significant decrease in blood GSH concentration in both patients and animals with various systemic $\mathrm{c}^{28-31}$ and ocular ${ }^{42-45}$ diseases. Although recent studies have shown that there are altered levels of GSH and GSH activity in the trabecular meshwork and aqueous humor of patients with glaucoma, ${ }^{23-26}$ to date no study has demonstrated an abnormal GSH level in the blood of patients with POAG.

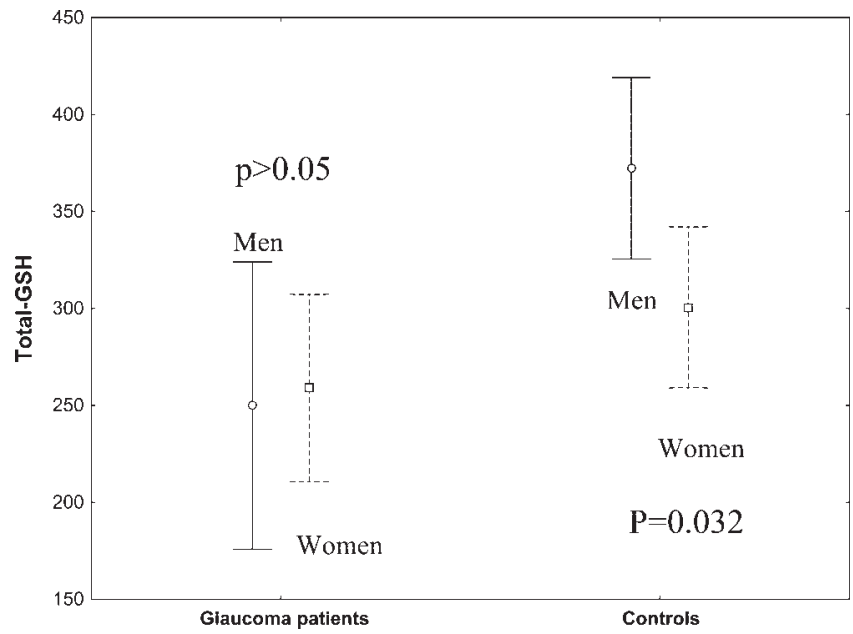

Figure 6. Men demonstrated higher levels of t-GSH than did women in the control group but not in the POAG group. 
TABLE 4. Blood Glutathione Levels in the Study Groups

\begin{tabular}{lccc}
\hline \multicolumn{1}{c}{ Parameter } & $\begin{array}{c}\text { Glaucoma Patients } \\
(\boldsymbol{n}=\mathbf{2 1})\end{array}$ & $\begin{array}{c}\text { Control Subjects } \\
(\boldsymbol{n}=\mathbf{3 4 )}\end{array}$ & $\boldsymbol{P}$ \\
\hline GSH (nmol) & $225.27 \pm 83.03$ & $332.23 \pm 98.50$ & 0.010 \\
GSSG (nmol) & $31.79 \pm 18.61$ & $35.34 \pm 17.64$ & $>0.05$ \\
Redox index (GSH/GSSG) & $9.44 \pm 6.34$ & $10.52 \pm 6.69$ & $>0.05$ \\
t-GSH (nmol) & $256.28 \pm 83.03$ & $333.04 \pm 99.92$ & 0.006 \\
\hline
\end{tabular}

Circulating GSH can be depleted either by subjecting cells to oxidative stress, or by inhibition of synthesis. In patients with glaucoma, due to a high level of oxidative stress, ${ }^{22-26} \mathrm{GSH}$ could be overused in reactions that result in GSSG production. ${ }^{51}$ Nevertheless, our study groups demonstrated similar GSSG levels. One explanation could be that the GSSG resulted from the reaction between GSH, and ROS is rapidly reduced back to GSH, thus completing the normal redox cycle. ${ }^{60}$ In normal conditions, GSSG is quite effective in maintaining GSH in its reduced state. ${ }^{60}$ Our patients with glaucoma, however, demonstrated a significantly lower GSH level than control subjects, indicating that this mechanism played a role in our model and implying that the protection against ROS afforded by GSH could be reduced in patients with this disease, possibly due to a defective redox cycle.

Another possible reason for low GSH levels in our patients with glaucoma could be defective intracellular synthesis. The liver is the major site for GSH synthesis. ${ }^{61}$ The precursors necessary for this synthesis are L-glutamate, L-cysteine, and L-glycine and the first step of the reaction, catalyzed by GSC, is controlled by a negative feedback from its end product, GSH. ${ }^{62}$ In the present study, however, the level of GSH in patients with glaucoma was found to be low, therefore suggesting that the limiting factors in this case could be the availability of precursors of GSH. ${ }^{60}$ Although both glutamate and glycine are important, it seems that the major determinant of the rate of GSH synthesis is the availability of the amino acid cysteine (Cys). ${ }^{63}$ Cysteine results from the metabolism of homocysteine (Hcy) in the presence of cofactors such as vitamins B6, B12, and folate. Any interruption in the Hcy-Cys pathway could result, not only in the accumulation of the former but also in less available quantities from the second amino acid. In high concentrations, Hcy has been implicated in the etiology of various cardio- and cerebrovascular diseases. ${ }^{64-66}$ Because vascular risk factors are implicated in the etiology of POAG, ${ }^{5-9,12-21}$ one could hypothesize that abnormal levels of

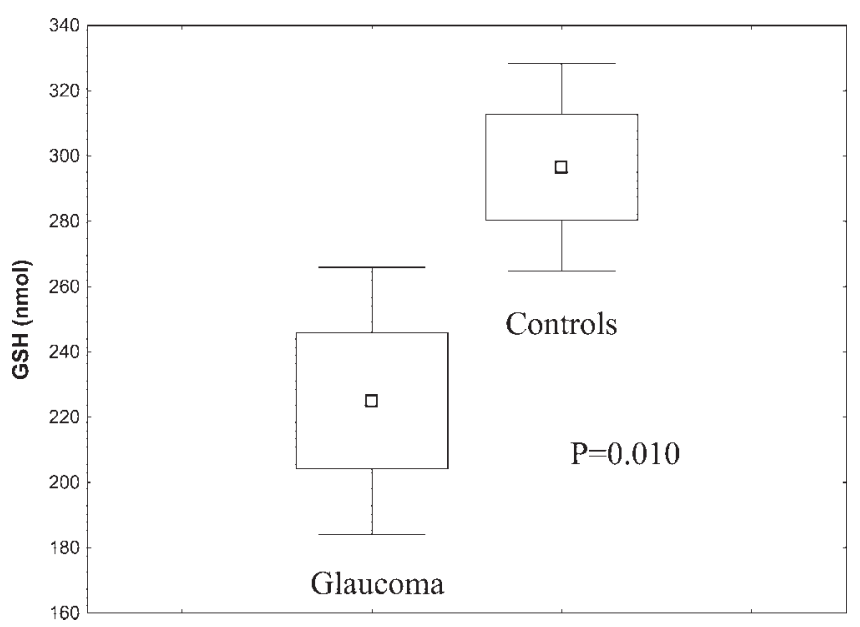

Figure 7. Patients with glaucoma exhibited lower levels of GSH than did control subjects. circulating Hcy are to be found in patients with this disease. The results of recent research published on this subject have been contradictory. Bleich et al. ${ }^{67}$ reported higher plasma Hcy levels in patients with POAG than in control subjects whereas, in a more recent study, Wang et al. ${ }^{69}$ did not detect any significant difference in plasma Hcy between patients with POAG and control subjects. In the present study, we did not seek to quantify the plasma Hcy in our patients and control subjects. We suggest that the abnormal low level of GSH in patients with glaucoma could be at least partially explained by a lower availability of Cys due to an abnormal Hcy-Cys metabolic pathway.

A low level of circulating GSH may also result in a higher rate of oxidative reactions that reduce the bioavailability of NO. Several studies have shown that NO is also involved in the regulation of systemic hemodynamics, ${ }^{69,70}$ with disturbed NO homeostasis contributing to alterations in systemic vascular diseases such as hypertension or diabetes, in which basal formation of NO is impaired. ${ }^{71,72}$ It has also been hypothesized that a low NO production has a major effect on the equilibrium between the endothelial vasoconstrictive and vasodilatory factors at the ocular level that could also result in a decreased OBF in susceptible patients with glaucoma. ${ }^{73}$ In addition to the hemodynamic role, NO has also been shown to induce relaxation of the trabecular meshwork and the ciliary muscle, resulting in a decrease in IOP. ${ }^{74}$ Any disturbance in the NO balance could therefore act both at the ocular and systemic levels ${ }^{47}$ and have dramatic consequences on the progression of glaucoma. It can been suggested that in some patients with glaucoma, not only the high level of IOP but also the occurrence of vasospasm ${ }^{75}$ and thrombosis ${ }^{76}$ can be the result of reduced NO bioavailability due to low levels of circulating GSH.

In conclusion, our study demonstrated for the first time that untreated patients with POAG exhibit low levels of circulating

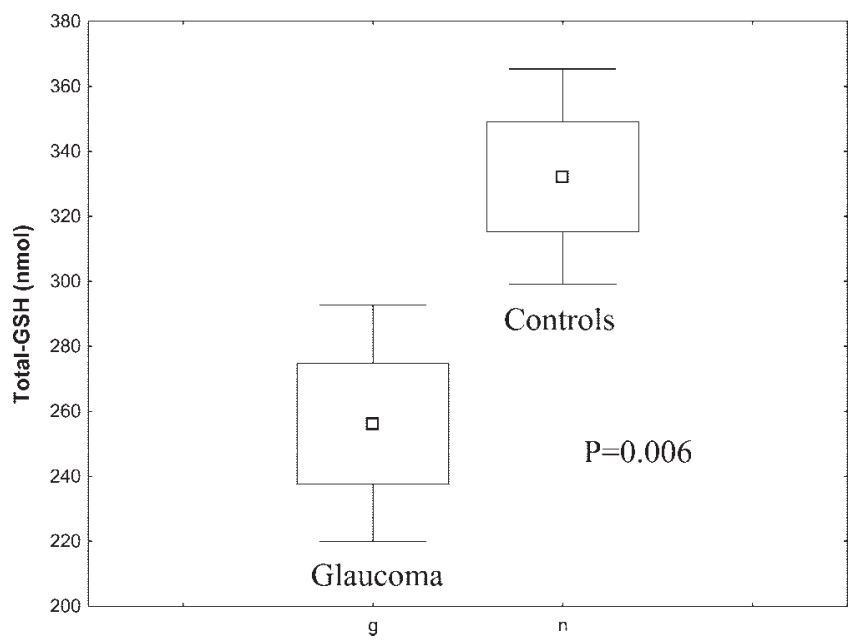

Figure 8. Patients with glaucoma exhibited lower levels of t-GSH than did control subjects. 
GSH, suggesting a general compromise to antioxidative defense. Further investigations are needed, to identify the cause of this biochemical deficiency.

\section{References}

1. Van Buskirk EM, Cioffi GA. Glaucomatous optic neuropathy. Am J Ophthalmol. 1992;113:447-452.

2. Flammer J, Orgul S, Costa VP, et al. The impact of ocular blood flow in glaucoma. Prog Retin Eye Res. 2002;21:359-393.

3. Krakau CET. Intraocular pressure elevation: cause or effect in chronic glaucoma? Ophthalmologica. 1981;182:141-147.

4. Bonomi L, Marchini G, Marraffa M, Morbio R. The relationship between intraocular pressure and glaucoma in a defined population: data from the Egna-Neumarkt glaucoma study. Ophthalmologica. 2001;215:34-38.

5. Rojanapongpun P, Drance SM, Morrison BJ. Ophthalmic artery flow velocity in glaucomatous and normal subjects. Br J Ophthalmol. 1993;77:25-29.

6. Nicolela MT, Hnik P, Drance SM. Scanning laser Doppler flowmeter study of retinal and optic disk blood flow in glaucomatous patients. Am J Ophthalmol. 1996;122:775-783.

7. Kaiser HJ, Schötzau A, Flammer J. Blood flow velocity in the extraocular vessels in chronic smokers. Br J Ophthalmol. 1997; 81:133-135.

8. Butt Z, O'Brien C, McKillop G, Aspinall P, Allan P. Color Doppler imaging in untreated high- and normal-pressure open-angle glaucoma. Invest Ophthalmol Vis Sci. 1997;38:690-696.

9. Findl $\mathrm{O}$, Rainer $\mathrm{G}$, Dallinger $\mathrm{S}$, et al. Assessment of optic disk blood flow in patients with open-angle glaucoma. Am J Ophthalmol. 2000;130:589-596.

10. Flammer J. The vascular concept of glaucoma. Surv Ophthalmol. 1994;38(suppl):S3-S6.

11. O'Brien C. Vasospasm and glaucoma. Br J Ophthalmol. 1998;82: 855-857.

12. Chung HS, Harris A, Evans DW, Kagemann L, Garzozi HJ, Martin B. Vascular aspects in the pathophysiology of glaucomatous optic neuropathy. Surv Ophthalmol. 1999;43(suppl 1):S43-S50.

13. Anderson DR. Introductory comments on blood flow autoregulation in the optic nerve head and vascular risk factors in glaucoma. Surv Ophthalmol. 1999;43(suppl 1):S5-S9.

14. Gherghel D, Orgül S, Dubler B, Lübeck P, Gugleta K, Flammer J. Is vascular regulation in the central artery altered in persons with vasospasm? Arch Ophthalmol. 1999;117:1359-1362.

15. Gherghel D, Orgül S, Gugleta K, Gekkieva M, Flammer J. Relationship between ocular perfusion pressure and retrobulbar circulation in glaucoma patients with progressive damage. Am J Ophthalmol. 2000;130:597-605.

16. Hosking SL, Harris A, Chung HS, et al. Ocular haemodynamic responses to induce hypercapnia and hyperoxia in glaucoma. $\mathrm{BrJ}$ Ophthalmol. 2004;88:406-411.

17. Kaiser HJ, Flammer J, Graf T, Stümpfig D. Systemic blood pressure in glaucoma patients. Graefes Arch Clin Exp Ophthalmol. 1993; 231:677-680.

18. Hayreh SS, Zimmerman MB, Podhajsky P, Alward WL. Nocturnal arterial hypotension and its role in optic nerve head and ocular ischemic disorders. Am J Ophthalmol. 1994;117:603-624.

19. Bechetoille A, Bresson-Dumont H. Diurnal and nocturnal blood pressure drops in patients with focal ischemic glaucoma. Graefes Arch Clin Exp Ophthalmol. 1994;232:675-679.

20. Tielsch JM, Katz J, Sommer A, Quigley HA, Javitt JC. Hypertension, perfusion pressure, and primary open-angle glaucoma: a population-based assessment. Arch Ophthalmol. 1995;113:216-221.

21. Graham SL, Drance SM, Wijsman K, Douglas GR, Mikelberg FS. Ambulatory blood pressure monitoring in glaucoma: the nocturnal dip. Ophthalmology. 1995;102:61-69.

22. Alvarado J, Murphy C, Juster R. Trabecular meshwork cellularity in primary open-angle glaucoma and nonglaucomatous normals. $O p h$ thalmology. 1984;91:564-579.

23. Nguyen KPV, Weiss H, Karageuzian LN, et al. Glutathione reductase of calf trabecular meshwork. Invest Ophthalmol Vis Sci. $1985 ; 26: 887-890$.
24. Levin LA, Clark JA, Johns LK. Effect of lipid peroxidation inhibition on retinal ganglion cell death. Invest Ophthalmol Vis Sci. 1996; 37:2744-2749

25. Izzotti A, Sacca SC, Cartiglia C, De Flora S. Oxidative deoxyribonucleic acid damage in the eyes of glaucoma patients. Am J Med. 2003;114:638-646.

26. Ferreira SM, Lerner SF, Brunzini R, Evelson PA, Llesuy SF. Oxidative stress markers in aqueous humor of glaucoma patients. $A m \mathrm{~J}$ Ophthalmol. 2004;137:62-69.

27. Valencia E, Hardy G, Marin A. Glutathione: nutritional and pharmacologic viewpoints: Part VI. Nutrition. 2002;18:291-292.

28. Ahsan H, Ali A, Ali R. Oxygen free radicals and systemic autoimmunity. Clin Exp Immunol. 2003;131:398 - 404.

29. Videla LA, Guerri C: Glutathione and alcohol. In: Vina J, ed. Glutathione: Metabolism and Physiological Functions. Boca Raton, FL: CRC Press; 1990:57-67.

30. Beutler E, Gelbart T. Plasma glutathione in health and in patients with malignant disease. J Lab Clin Med. 1985;105:581-584.

31. Buhl R, Holroyd KJ, Mastrangeli A, et al. Systemic glutathione deficiency in symptom-free HIV-seropositive individuals. Lancet. 1989;2:1294-1298.

32. Ferdinandy P, Schulz R. Nitric oxide, superoxide and peroxynitrite in myocardial ischemia-reperfusion injury and preconditioning. Br J Pharmacol. 2003;138:532-543.

33. Erden M, Bor NM. Changes of reduced glutathione, glutathione reductase and glutathione peroxidase after radiation in guinea pigs. Biochem Med. 1984;31:217-227.

34. Portakal O, Inal M. Effects of pentoxyfilline and coenzyme Q10 in hepatic ischemia/reperfusion injury. Clin Biochem. 1999;36:461466.

35. Richer SP, Rose RC. Water soluble antioxidants in mammalian aqueous humor: interaction with UV and hydrogen peroxide. Vision Res. 1998;38:2881-2888.

36. Benedich A. Antioxidant micronutrients and immune responses. Ann NY Acad Sci. 1990;587:168-180.

37. Pompella A, Visvikis A, Paolicchi A, De Tata V, Casini AF. The changing faces of glutathione, a cellular protagonist. Biochem Pharmacol. 2003;66:1499-1503.

38. Townsend DM, Tew KD, Tapiero H. The importance of glutathione in human disease. Biomed Pharmacother. 2003;57:145-155.

39. Harding JJ. Free and protein-bound glutathione in normal and cataractous human lenses. Biochem J. 1970;117:957-960.

40. Spector A. Oxidative stress-induced cataract: mechanism of action. FASEB J. 1995;9:1173-1182.

41. Lou MF. Redox regulation in the lens. Prog Retin Eye Res. 2003; 22:657-682.

42. Donma O, Yorulmaz E, Pekel H, Suyugul N. Blood and lens lipid peroxydation and antioxidant status in normal individuals, senile and diabetic cataractous patients. Curr Eye Res. 2002;25:9-16.

43. Cicik E, Tekin H, Akar S, et al. Interleukin-8, nitric oxide and glutathione status in proliferative vitreoretinopathy and proliferative diabetic retinopathy. Ophthalmic Res. 2003;35:251-255.

44. Nowak M, Swietochowska E, Wielkoszynski T, et al. Changes in blood antioxidants and several lipid peroxidation production in women with age-related macular degeneration. Eur J Ophthalmol. 2003;13:281-286.

45. Cai J, Nelson KC, Wu M, Sternberg P, Jones DP. Oxidative damage and protection of the RPE. Prog Retin Eye Res. 2003;19:205-221.

46. Yang J, Tezel G, Patil RV, Romano C, Wax MB. Serum antibody against glutathione S-transferase in patients with glaucoma. Invest Ophthalmol Vis Sci. 2001;42:1273-1276.

47. Galassi F, Renieri G, Sodi A, Ucci F, Vannozzi L, Masini E. Nitric oxide proxies and ocular perfusion pressure in primary open angle glaucoma. Br J Ophthalmol. 2004;88:757-760.

48. Beard KM, Shangari N, Wu B, O'Brien PJ. Metabolism, not autoxination, plays a role in alpha-oxoaldehyde- and reducing sugarinduced erythrocyte GSH depletion: relevance for diabetes mellitus. Mol Cell Biochem. 2003;252:331-338.

49. Jones DP, Coates RJ, Flagg EW, et al. Glutathione in foods listed in the National Cancer Institute's health habits and history food frequency questionnaire. Nutr Cancer. 1992;17:57-75. 
50. Anderson ME: Glutathione. In: Punchard NA, Kelly FJ, eds. Free Radicals: A Practical Approach. Oxford, UK: Oxford University Press; 1996:213-226.

51. Anderson ME, Meister A. Dynamic state of glutathione in blood plasma. J Biol Chem. 1980;255:9530-9533.

52. Jones DP, Carlson JL, Samiec PS, et al. Glutathione measurement in human plasma: evaluation of sample collection, storage and derivatization conditions for analysis of dansyl derivatives by HPLC. Clin Chim Acta. 1998;275:175-184.

53. Tietze F. Enzymic method for quantitative determination of nanogram amounts of total and oxidized glutathione: application to mammalian blood and other tissues. Anal Biochem. 1969;27:502522.

54. Punchard NA, Watson DJ, Thompson RPH. Analysis of glutathione in endothelial cells grown in 96 well microtitre plates. Biochem Soc Trans. 1994;22:198S.

55. Matsubara LS, Machado PEA. Age-related changes of glutathione content, glutathione reductase and glutathione peroxidase activity of human erythrocytes. Braz J Med Biol Res. 1991;24:449-454.

56. Lang CA, Naryshkin S, Schneider DL, Mills BJ, Lindeman RD. Low blood glutathione levels in healthy aging adults. J Lab Clin Med. 1992;120:720-725.

57. Erden-Inal M, Sunal E, Kanbak G. Age-related changes in glutathione redox system. Cell Biochem Funct. 2002;20:61-66.

58. Knight JA. The biochemistry of aging. Adv Clin Chem. 2000;35: $1-62$.

59. Flagg EW, Coates RJ, Jones DP, Eley JW, Gunter EW, Jakson B, Greenberg RS. Plasma total glutathione in humans and its association with demographic and health-related factors. BrJ Nutr. 1993; 70:797-808.

60. Wang W, Ballatori N. Endogenous glutathione conjugates: occurrence and biological functions. Pharmacol Rev. 1998;50:335-355.

61. Deleve LD, Kaplowitz N. Glutathione metabolism and its role in hepatotoxicity. Pharmacol Ther. 1991;52:287-305.

62. Richman PG, Meister A. Regulation of gamma-glutamylcysteine synthetase by nonallosteric feedback inhibition by glutathione. J Biol Chem. 1975;250:1422-1426.
63. Lu SC. Regulation of hepatic glutathione synthesis: current concepts and controversies. FASEB J. 1999;13:1169-1183.

64. McCully KS. Vascular pathology of homocysteinemia: implications for the pathogenesis of arteriosclerosis. Am J Patbol. 1969;56: 111-128.

65. Clarke R, Daly L, Robinson K, et al. Hyperhomocysteinemia: an independent risk factor for vascular disease. N Engl J Med. 1991; 324:1149-1155.

66. Selhub J, Jaques PF, Bostom AG, et al. Association between plasma homocysteine concentration and extracranial carotid artery stenosis. N Engl J Med. 1995;332:286-291.

67. Bleich S, Junemann A, Von Ahsen N, et al. Homocysteine and risk of open-angle glaucoma. J Neural Transm. 2002;109:1499-1504.

68. Wang G, Medeiros FA, Barshop BA, Weinreb RN. Total plasma homocysteine and primary open-angle glaucoma. Am J Ophthalmol. 2004;137:401-406.

69. Vallance P, Collier J, Moncada S. Nitric oxide synthesized from L-arginine mediates endothelium dependent dilatation in human veins in vivo. Cardiovasc Res. 1989;23:1053-1057.

70. Vallance P, Chan N. Endothelial function and nitric oxide: clinical relevance. Heart. 2001;85:342-350.

71. Calver A, Collier J, Moncada S, Vallence P. Effect of local intraarterial NG-monomethyl-L-arginine in patients with hypertension: the nitric oxide dilator mechanism appears abnormal. J Hypertens. 1992;10:1025-1031.

72. Chan NN, Vallance P, Colhun HM. Nitric oxide and vascular responses in Type I diabetes. Diabetologia. 2000;43:137-147.

73. Schmetterer L, Polak K. Role of nitric oxide in the control of ocular blood flow. Prog Retin Eye Res. 2001;20:823-847.

74. Wiederholt M, Sturm A, Lepple-Wienhues A. Relaxation of trabecular meshwork and ciliary muscle by release of nitric oxide. Invest Ophthalmol Vis Sci. 1994;35:2515-2520.

75. Pache M, Dubler B, Flammer J. Peripheral vasospasm and nocturnal blood pressure dipping: two distinct risk factors for glaucomatous damage? Eur J Ophthalmol. 2003;13:260-265.

76. O'Brien C, Butt Z, Ludlam C, Detkova P. Activation of the coagulation cascade in untreated primary open angle glaucoma. $O p b$ thalmology. 1997;104:725-729. 